\title{
The Usefulness of Applied Econometrics to the Policymaker
}

\author{
An Address by DARRYL R. FRANCIS, President, Federal Reserve Bank of St. Louis, \\ at the National Association of Business Economists Seminar, \\ Chicago, Illinois, April 4, 1973
}

I

AM DELIGHTED with the invitation to be with you today and have this opportunity to present a few of my views regarding the role of applied econometrics to the policymaker.

Since I am not a builder of econometric models or a practicing econometrician or statistician, I shall speak today as a consumer of the results of econometric models. In broad terms I shall discuss what I expect from my research staff and how I fold the products of their labors into my policy recommendations.

Policymakers stabilization actions are arrived at through their judgment about the general course of economic activity and the effectiveness of various tools available to them. All policymakers have some view of how the economy operates and how their actions affect the economy. This concept or hypothesis is usually based on years of experience and generally is not formulated as rigorously as an econometric model.

I believe that the concepts policymakers form about the operation of the economy should be constantly subjected to rigorous scientific analysis. Econometric models provide a valuable means of formulating and testing our hypotheses about the economy which can then be subjected to statistical analysis. In other words, we can determine whether om behefs hold water or have big holes in them.

Before getting into specifies, let me make a few general remarks about the context within which I see a role for scientific research. Most of what has been done by our staff over the years has begun with the formulation of testable, and therefore deniable, statements or hypotheses. Specifically, we frequently be- gin merely with the statement of a policymaker to the effect that if a specific event should occur, then certain subsequent events will occur. We then seek to formulate such a statement into a hypothesis in such a way that it is not a truism. To do so, we state the conditions which would be acceptable as a denial or rejection of the hypothesis.

Let me illustrate the importance of this by doing the opposite. Suppose someone makes a statement such as "More rainfall may or may not result in a larger com crop." That statement is empty of content since there is no event which would falsify it. In a nutshell, to engage in worthwhile research, we must be willing to be wrong. This has been the underlying philosophy of our research efforts. We seek to pursue our theoretical formulation and empirical testing in a professional manner, and then to present our results for all to examine. If subsequent events should prove us wrong, then we will accept it. In this manner economic knowledge is advanced.

As a Federal Reserve policymaker I must live in the real world. Therefore, advice from my staff that I should support a policy that would shift the LM curve is of very little use to me. As a member of the Federal Open Market Committee, I know that the actions I can vote for are changes in Federal Reserve holdings of Government securities. As President of a Federal Reserve Bank, I can recommend to our Board of Directors that they should submit a change in our Banks' discount rate. I cannot recommend to the Open Market Committee that the LM curve should be shifted one way or another. I can only recommend actions in terms of the instruments at hand. The justification for my position must be couched in terms of the probable effects on prices and employment. 
In recent years, especially with the advent of computers, there has been a great surge in the amount of mathematics and statistics used by economists. Although the mathematical trappings of economics may not seem too impressive to trained mathematicians, to most policymakers who have only a limited background in math, they pose a formidable barrier to understanding how economists derive their results. The bewildering struggles that occur between model builders over specification errors, structural versus reduced-form models, recursive versus non-recursive systems, etc., are meaningless to most policymakers.

This is not meant to deny the usefulness of math and statistics. These are very powerful tools, and their use has helped to advance knowledge in many fields of science. However, math is not an empirical science. When it comes down to the time of making a policy recommendation, I must still have a concrete interpretation in terms of open market operations. Also, beyond being told what to expect from a given policy action, I want to have some understanding of how the results are obtained.

The type of economic models that policymakers use depends largely upon the goals of their business. For example, the goal of General Motors is to produce and sell automobiles in order to maximize the net wealth of their stockholders. Therefore, GM policymakers would be interested in understanding the factors influencing the demand for autos and being able to forecast such demand.

The goal of the Federal Reserve, at least as I view it, is to promote high-employment growth without inflation. As a monetary policymaker, I am interested in what the Fed can do to achieve these goals. Therefore, I have directed our research staff to investigate the process by which Federal Reserve actions influence economic activity.

First, I wanted to determine what measure of Federal Reserve actions was most closely related to aggregate economic activity. Through extensive research we have concluded that changes in the money stock provide a highly reliable means of gauging the effect of monetary actions on total spending. However, recognition of this fact alone was only half the battle. To be at all useful in policy recommendations, it was necessary to determine whether, with its available policy instruments, the Federal Reserve could control the growth rate of money. Study of other economists' work, as well as our own investigative efforts, have proved conclusively that the money stock can be controlled with a relatively high degree of accuracy.
I think it is important at this point to make a distinction between monetary actions and monetary policy. For my purposes I am not solely interested in a measure of the intentions of policymakers. I am primarily interested in the results of their actions. If the effect of monetary actions is to accelerate money stock growth and hence accelerate inflation, that is of interest to me even if the intent of policy was to keep interest rates from rising.

If his research is to be of use to a policymaker, an economist must be able to tell me the results to be expected from a particular course of action. For example, if the Open Market Committee takes some action, such as directing the Trading Desk at the New York Federal Reserve Bank to slow money stock growth, I would like to know what this means in terms of the growth of total spending, output, and prices. There are two extreme situations which are not very useful to policymakers. One involves magnitudes which they control absolutely, but which have no effect on, or any relationship to, an ultimate policy objective. The other involves magnitudes which seem to be good causal predictors, but which are completely outside the control of the policymakers.

An economist must state his recommendations in a form that has empirical content. I am not primarily interested in statements that express relationships in abstract terms. I want to know what operations to direct the Desk to perform and how and when the performance of these operations will affect the prices people pay for goods and services and the number of people employed.

Therefore, it is not enough for my research staff to tell me that the Fed can control the money stock. As a member of the Open Market Committee, I know the Federal Reserve buys and sells Government securities; it does not fly a blimp across the land dumping out money. The assertion "the Fed can control the money stock" must be given empirical content in terms of what the Fed can directly control. The result of this demand for an operational procedure has led us to the use of the monetary base concept and the development of a procedure for determining the effects of a growth rate of base on growth of the money stock.

Here, I feel it necessary to say that I think it should be required of others who recommend that the Federal Reserve control different variables, such as interest rates, that they also provide policymakers with an operational means of achieving this control. It is wrong to accept at face value the statement the 
"Fed can control interest rates" without the corresponding explanation of how the Fed can do this, and what the consequences would be of doing so.

As a policymaker, I am primarily concemed with projection of where the ultimate goals are tending and what will be the effect on these goals if, for instance, the rate of growth of the money stock is altered. Therefore, we build models to help us understand the effect of growth of the money stock on policy goals.

As an example of our attempts to use models to understand the effects of monetary policy on the economy, I could mention the so-called "St. Louis Model." The original equation of this model was developed to test competing conjectures about the relative strengths of the growth of the money stock and fiscal actions. How do monetary and fiscal policy actions interact? Does money matter? Can the Fed continue an expansionary policy and force fiscal policy to bear the burden of restraint? As you can see, these are questions of great importance to a policymaker.

Once the computers have stopped running and my research staff has analyzed the results, I consider these results in my policy recommendations, keeping several points in mind. First, I am aware that no model is the absolute truth. All models have had their hours of glory in addition to their periods that their creators would prefer not to mention. Second, when attempting to see into the future, it is useful to compare the results of more than one model. When the results diverge substantially, this is frequently of more value than when all models give pretty much the same results. A divergence forces us to examine the reasons for the discrepancies and carefully think about the implications of the causes of these differences. Third, all the results of models must be examined to see if they are consistent with our accumulated evidence from history, theory, and practical experience.

My personal preference is for small models, rather than large models. This stems partly from my view that the Federal Reserve should be concerned with the aggregate effects of policy, and should leave the allocative effects to the operation of the market place. Also, not being a practicing econometrician, I prefer models whose operation I can understand. I am willing to trade some so-called "structural richness," much of which refers to matters I do not consider to be the proper concem of monetary policymakers, for an ability to understand the process by which the model arrives at its results. I have never been willing to simply accept the results of any model. As a policy- maker, I want to know as fully as possible the basis for my policy recommendations.

In addition to forecasting, policymakers are also interested in planning. Forecasts give us some idea of where the economy is headed, given past policy actions. However, our job does not end with attempts to analyze the effects of policy actions on the economy and to forecast subsequent events. We must also engage in planning. This involves determining desired future values for prices and employment and deciding how to achieve these goals. At the planning stage, both understanding of the economic process and forecasting future developments must blend together. When we seek to influence the course of prices and employment, our research staff is required to use all of its knowledge about forces influencing the economy in order to monitor forecasts of the effects of changes in policy.

These forecasts, upon which we depend in deciding our course of action, involve some assessment of the pattern of developments to be expected following a certain action. Let me be more specific. It is not sufficient for an economist to tell us that a slower growth in money will eventually result in a slower rate of price increase. As a policymaker, I would like to have better information as to the specific open market transactions that would achieve, with a high probability, a desired growth of money. I am also vitally concemed with the time distribution to be expected with regard to changes in prices and output for a given change in the rate of growth of money. Then I want to know how some tangible results can be expected with regard to prices and output, and how the pattern will appear in the data subsequently reported.

Economic research can never tell policymakers what are "good" or "just" policy goals. However, by giving the policymakers an indication of the expected results of different policy actions, economic research can provide a valuable service.

As much as politicians hate to admit it, we live in a world of trade-offs. One of the gravest diseases afflicting rational policymaking is the refusal to accept the fact that we cannot always "have our cake and eat it too." I well remember a couple of years ago the recommendation of the Joint Economic Committee of Congress that called for the attainment of a 2 percent rate of inflation and a 3 percent unemployment rate in a short period of time. All accumulated economic research indicated that these two goals were mutually incompatible in the foreseeable future. 
Frequently in the past six years we at the Federal Reserve have found ourselves perched on the horns of a dilemma where failure to slow money growth meant accelerating inflation, but slowing money growth meant rising interest rates. Unfortunately, rather than recognize the short-run trade-off implied by economic research, we have ended up with both accelerating inflation and higher interest rates, rather than less inflation and lower interest rates which longer-range policy planning could have provided.

Monetary policy cannot "fine-tune" out all fluctuations in economic activity. However, given the current state of economic knowledge, monetary policy can avoid inducing a high rate of inflation or a recession in the economy. Thus, I would like policy to remain neutral with regard to cyclical movements in economic activity rather than run the risk of reinforcing them. I believe econometric models have been an aid to policymakers in outlining the available alternatives, and, therefore, have added to rational policymaking.

I would like to conclude my remarks by liberally paraphrasing from an article that appeared in the Quarterly Journal of Economics some years ago."

It seems that in a certain kingdom there was a school for the education of princes approaching manhood. Since the king and his court spent much of their time playing chess, it was decided that the subject called "games" should be added to the curriculum of the school. A wizard of the school was assigned to develop the course.

Since the wizard had never played chess, he corresponded with wizards in other kingdoms who told him that the main concern was that the course in "games" should be rigorous and intellectually challenging. Long ago the wizards concluded that chess, as actually played, was so complicated it was impossible to develop the principles and rules necessary to teach it in the classroom. Therefore, they introduced a number of simplifying assumptions which tidied-up the game and made it much easier to teach and give exams.

Permission to exerpt passages was granted in April 1973. The original article appeared in the May 1965 Quarterly Joturnal of Economics, pp. 209-211.
Having received a copy of the rules of this game the wizard began teaching it to his students, passing those who learned it well, and failing those who did not adequately master all the rules. The wizard maintained an active correspondence with wizards in other kingdoms, gradually modifying the rules of this game. For convenience, they referred to the game as chess, although it was taken for granted that everyone knew their game was not quite the same as the chess played in the real world.

One day the king summoned the wizard and asked him to describe the method used to teach chess in school. The king was naturally amazed to hear that, in classroom chess, all pieces moved in straight lines and the wizard used terms like "jumping men" and "double jumping" which were Greek to the king; the wizard never referred to things the king was familiar with such as queens, rooks, bishops, pawns, and knights.

Somewhat puzzled, the king asked the wizard if he had ever observed chess being played in the real world. The wizard replied, "no, but I do carry on correspondence with other wizards. This is better since everyone knows wizards are smarter than chess players."

Then the king asked "After finishing your course, are the princes better chess players because of what they learned in your class?"

The wizard replied, "No offense, sir, but we wizards view the purpose of our courses as being to teach the princes to think, not to prepare them for a mere vocation."

The moral of this little tale for the economics profession is: "An education in checkers does not prepare one for a life of chess."

The moral for the businessman is: "A consultant who wants to play his own game, rather than yours, is worthless."

Like the king in the fable, I too want to be a better chess player. However, I do not just want to learn the abstract rules of the game - I must play in the real world.

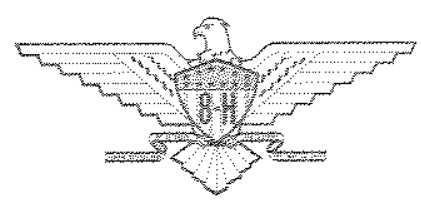

